\title{
Expression of recombinant proteins in insect cells by their direct infection with Escherichia coli transformed with baculovirus bacmids
}

\author{
X. YU*, J. HUA, G. HU, J. ZHANG, L. MA* \\ Institute of Biochemistry and Molecular Biology, College of Life Science, Hubei University, Wuhan 430062, P. R. China
}

Received February 11, 2013; accepted February 24, 2014

\begin{abstract}
Summary. - The baculovirus-insect cell expression system (BES), one of the most popular systems for expression of eukaryotic proteins, was known to have drawbacks such as laborious manipulation of large-size baculovirus bacmids and the transfection procedure. These problems could be eliminated by direct infection of eukaryotic cells with nonpathogenic bacteria harbouring the respective gene - bactofection. However, it was unknown whether this system could be applied to insect cells. Therefore, in this study, the possibility of delivery of enhanced green fluorescent protein (EGFP) gene as a marker into the insect cell lines Sf9 and BmN-SWU1 using the above-mentioned approach with the Bac-to-Bac system was investigated. Using a simple co-incubation of Escherichia coli strains containing recombinant baculovirus bacmids with the EGFP gene and insect cells, it was possible to demonstrate the EGFP expression in these cells and to obtain high-titer recombinant baculoviral stocks. Furthermore, BmN-SWU1 cells proved more susceptible to the used E. coli strains than Sf9 cells. However, the co-expression of invasin and listeriolysin-O, known to enhance the E. coli-mediated gene delivery to mammalian cells, with EGFP, had no effect on insect cells. Summing up, this study proved that a heterologous gene can be efficiently delivered and expressed in insect cells by their simple incubation with non-pathogenic $E$. coli strains harboring recombinant baculovirus bacmids with the respective gene.
\end{abstract}

Keywords: baculovirus; bacmid; EGFP; Escherichia coli; insect cell

\section{Introduction}

The baculovirus-insect cell expression system (BES) is widely used in many fields, including surface display of heterologous proteins, protein engineering, drug discovery, and gene therapy (Kost et al., 2005). Advantages of the system include high packaging capacity, high level of protein expression, simultaneous expression of hetero-oligomeric complexes, advanced post-translational modification, and biosafety (Belzhelarskaia, 2002; Ashour et al., 2007). These attributes have increased the

*Corresponding authors. E-mail: yxiaolan@163.com, malixin9@ hotmail.com; phone: +86-27-88666349.

Abbreviations: AcNPV = Autographa californica nuclear polyhedrosis virus; $\mathrm{BES}=$ baculovirus-insect cell expression system; $\mathrm{BmNPV}=$ Bombyx mori nuclear polyhedrosis virus; $\mathrm{BmN}$ SWU1 = ovarian cell line of Bombyx mori; EGFP = green fluorescent protein; $\mathrm{MOI}=$ multiplicity of infection; .i. = post infection; sf $9=$ Spodoptera frugiperda 9; t.o.i. = time of infection interest in utilizing baculoviruses in areas such as vaccine development, cancer therapy, antiviral therapy, tissue regeneration, and organ transplantation (Hu et al., 2008; Tani et al., 2008; Suzuki et al., 2009; Lin et al., 2010; Madhan et al., 2010; Wang and Balasundaram, 2010; Hitchman et al., 2011). Two main types of the baculovirus have been used; Autographa californica nuclear polyhedrosis virus (AcNPV) and Bombyx mori nuclear polyhedrosis virus (BmNPV). BmNPV plays an important role in protein engineering, because it has restricted hosts including cell lines derived from Bombyx mori and silkworm larvae, which are regarded as powerful and economical bioreactors (Maeda et al., 1985). Considerable progress has been made in BES recently, focusing on the construction of recombinant baculoviruses. Homologous recombination between foreign genes and the wild-type baculovirus genome DNA in vivo followed by plaque purification was initially used to obtain recombinant baculoviruses (Smith et al., 1983). The recombination efficiency was enhanced approximately 10 -fold by linearization of the wildtype viral DNA instead of the use of circular viral DNA (Kitts et 
al., 1990). The introduction of rare-cutting restriction sites, such as I-SceI, into the baculovirus genome DNA, and the Bac-to-Bac system (Invitrogen) based on site-specific transposition resulted in convenient and fast cloning of foreign genes in vitro (Ernst et al., 1994). The BmNPV Bac-to-Bac system was used to obtain recombinant BmNPV bacmids (Motohashi et al., 2005). The major challenge of BES is to achieve efficient transfer of large DNA fragments $(>100 \mathrm{~kb})$ into insect cells, which has limited the use of this system. A variety of reagents have been used to mediate the entry of genetic materials into cells, including calcium phosphate, peptides and lipid-based media. The uptake of DNA by cells occurs either by interacting directly with the cellular plasma membrane or by non-receptor mediated endocytosis (Bangham, 1992; Zabner et al., 1995). Although there are no size limits, only low amounts of the transfected DNA were delivered into the nucleus (Magin-Lachmann et al., 2004). In addition, electroporation is an alternative for introducing DNA into a wide variety of cell lines, but involves high costs (Potter and Heller, 2001).

In BES, low-copy number of viral bacmids augments difficulties for preparation of bacmids in vitro. Additionally, long-term stability of the bacmid DNA during the process of transfection is critical to obtain high-titer baculoviral stocks. Successive amplification of the virus is one way to harvest high amounts of baculovirus. However, defective interfering baculoviruses and spontaneous excision of the bacterial artificial chromosome (BAC) vector sequence occurs during serial passages (Lee and Krell, 1992; Pijlman et al., 2003). It is, therefore, necessary to reduce the number of virus passages, not only to avoid the accumulation of deficient virions but also to save labor or time.

Bacteria-mediated gene delivery into mammalian cells (bactofection) using both phagocytic and nonphagocytic cells has been reported (Courvalin et al., 1995; Grillot-Courvalin et al., 2002). DNA-encoded antigens for vaccination and efficient immune responses were induced using attenuated bacteria, such as Shigella, Salmonella and E. coli (Sizemore et al., 1995; Darji et al., 1997; Radford et al., 2002). Moreover, significant gene silencing was induced by nonpathogenic invasive $E$. coli strains producing shRNA in vitro and in vivo (Xiang et al., 2006). As a useful delivery tool in research areas such as vaccination and gene therapy, bacteria have the advantage of low cost, simple manipulation, quick delivery and large delivery capacity compared with viral and nonviral vectors (Pálffy et al., 2006). Therefore, bactofection would become a promising gene delivery method if the delivery efficiency could be improved. Transfer efficiency was enhanced markedly by means of gene modification such as invasin, encoded by the inv gene, and listeriolysin-O, encoded by the hly gene, which are largely responsible for entry into nonphagocytic cells expressing $\beta 1$-integrins and escaping from the entry vesicle, respectively (Grillot-Courvalin et al., 1998). Finally, a stable diaminopimelate auxotroph with impaired cell wall synthesis has been used to facilitate gene release by selfdestruction (Dietrich et al., 1998).
In this study, we attempted to deliver the EGFP gene as a marker into insect cells BmN-SWU1 and Sf9 using the Bac-to-Bac system, and a direct infection of insect cells with E. coli containing bacmids harbouring the respective gene. We succeeded in demonstrating the EGFP expression and high-titer recombinant baculovirus production in this system. Moreover, we proved that BmN-SWU1 cells are more suited for the given aim than Sf9 cells and invasin and listeriolysin-O do not enhance the gene delivery in this system.

\section{Materials and Methods}

Bacterial strains and plasmids. The E. coli bacterial strains XLGold, BL21, DH10Bac and BmDH10Bac (Motohashi et al., 2005) (kindly presented by Dr. Enoch Y. Park) were grown in LB medium containing appropriate antibiotics. The transfer vector pUltraBac, containing the egfp gene under the control of the late basic protein promoter $\left(\mathrm{P}_{\text {Basic }}\right)$ was a kind gift from Dr. Felix Freuler (Philipps et al., 2005). The plasmid pGB2Sinv-hly encoding both invasin and listeriolysin-O was a gift from Dr. Grillot-Courvalin C (GrillotCourvalin et al., 1998). The amplified egfp gene was inserted into the pET30a plasmid (Clontech) using the EcoRV and XhoI restriction sites to generate the recombinant plasmid pET30a/egfp.

Insect cells. The BmN-SWU1 cell line, originally established from ovarian tissue of Bombyx mori, was a gift from Dr. Lu Cheng (Southwest University, Chongqing, P. R. China). Sf9 cells and BmN-SWU1 cells were cultured in Grace's Insect Cell Culture Medium (Gibco BRL) supplemented with 10\% FBS (Si Jiqing, Hangzhou, P. R. China), $100 \mathrm{U} / \mathrm{ml}$ penicillin and $100 \mu \mathrm{g} / \mathrm{ml}$ streptomycin at $27^{\circ} \mathrm{C}$.

Preparation of transformed E. coli strains expressing EGFP. pET30a/egfp was transformed into competent E. coli BL21 cells to generate the strain E. coli BL21/egfp. The strain E. coli BL21/egfp/ $\Omega$ was obtained by co-transformation of pET30a/egfp and pGB2 2 inv$h l y$ into competent $E$. coli BL21 cells. The two bacterial strains were cultured in LB supplemented with $50 \mu \mathrm{g} / \mathrm{ml}$ kanamycin and/or $25 \mu \mathrm{g} / \mathrm{ml}$ spectinomycin, and $0.1 \mathrm{mmol} / \mathrm{l}$ IPTG was added and incubated for $2 \mathrm{hrs}$ to induce EGFP expression prior to infection.

The donor plasmid pUltraBac was transformed into competent E. coli $\mathrm{DH} 10 \mathrm{Bac}$ and E. coli BmDH10Bac cells following the manufacturer's instructions for the Bac-to-Bac Baculovirus Expression System (Invitrogen). Positive clones containing the recombinant baculovirus bacmids Ac/egfp and Bm/egfp were designated E. coli DH10Bac/egfp and E. coli BmDH10Bac/egfp, respectively. The pGB2Sinv-hly was transformed into competent E. coli DH10Bac/ egfp and E. coli BmDH10Bac/egfp cells, resulting in the strains E. coli $\mathrm{DH} 10 \mathrm{Bac} / \mathrm{gfp} / \Omega$ and $E$. coli $\mathrm{BmDH} 10 \mathrm{Bac} / \mathrm{egfp} / \Omega$, respectively. These strains were cultured in LB medium supplemented with $50 \mu \mathrm{g} / \mathrm{ml}$ kanamycin and/or $50 \mu \mathrm{g} / \mathrm{ml}$ spectinomycin.

Infection of insect cells with bacteria. Both Sf 9 and BmN-SWU1 cells $\left(1.0 \times 10^{6}\right.$ cells $\left./ \mathrm{ml}\right)$ were seeded into 24 -well plates. When the cells were at about $75 \%$ confluence, the bacterial cells in late logarithmic phase of growth were harvested by centrifugation and 
resuspended in Grace's Medium at $1.0 \times 10^{9} \mathrm{bacteria} / \mathrm{ml}$. The bacteria were added to the insect cells at different MOI and co-incubated for various periods of time. Then the insect cells were gently washed three times for $30 \mathrm{~min}$ with serum-free Grace's Medium supplemented with $50 \mu \mathrm{g} / \mathrm{ml}$ gentamicin, $50 \mu \mathrm{g} / \mathrm{ml}$ chloramphenicol and $50 \mu \mathrm{g} / \mathrm{ml}$ spectinomycin. After washing, the infected cells were incubated in complete Grace's Medium containing $50 \mu \mathrm{g} / \mathrm{ml}$ gentamicin, $50 \mu \mathrm{g} / \mathrm{ml}$ chloramphenicol and $50 \mu \mathrm{g} / \mathrm{ml}$ spectinomycin at $27^{\circ} \mathrm{C}$. The $\mathrm{P} 1$ generation baculoviral stocks were harvested from the infected cell culture at 5 days post infection (p.i.).

Assay of internalized bacteria. Extracellular bacteria were killed and removed by gently washing with serum-free Grace's Medium supplemented with $50 \mu \mathrm{g} / \mathrm{ml}$ gentamicin, $50 \mu \mathrm{g} / \mathrm{ml}$ chloramphenicol and $50 \mu \mathrm{g} / \mathrm{ml}$ spectinomycin after bacteria invasion. The internalized bacteria were released from insect cells with $0.2 \%$ Triton X-100 and viable bacterial counts were determined on LB agar plates containing appropriate antibiotics. The results were calculated as the mean \pm SD from triplicate assays.

Virus titration. The recombinant baculovirus bacmids Ac/egfp and Bm/egfp were extracted and purified with phenol-chloroform. Then the bacmids were transfected into the BmN-SWU1 and Sf9 cells using the CellFECTIN reagent (Invitrogen) according to the manufacturer's instructions. P1 generation baculoviral stocks were harvested from the transfected cell culture 5 days post-transfection. Viral stocks were serially diluted from $10^{-1}$ to $10^{-9}$ and seeded into 96-well plates. The viral titer was determined with the help of the EGFP marker (Cha et al., 1997). Cells expressing EGFP were observed by a Leica TCS NT confocal microscope, and the titers of the baculoviral stocks were calculated according to the $\mathrm{TCID}_{50}$ (Philipps et al., 2005). The titration results were obtained as the mean \pm SD from triplicate assays.

Expression of heterologous proteins in BmN-SWU1cells. BmNSWU1 cells were seeded into a $5.0 \times 7.0 \mathrm{~cm}^{2}$ flask. After the $75 \%$ confluence was reached, they were infected with baculoviruses at a MOI of 10 . Infected cells were collected at $40-48 \mathrm{hr}$ p.i. and lyzed with cell lysis buffer $(50 \mathrm{mmol} / \mathrm{l}$ Tris- $\mathrm{HCl}, 5 \mathrm{mmol} / \mathrm{l} 2$-hydroxy-1ethanethiol, $100 \mathrm{mmol} / \mathrm{l} \mathrm{KCl}, 1 \mathrm{mM}$ Phenylmethanesulfonyl fluoride, 1\% NP-40) for western blot analysis. Anti-His/GST antibody (Santa Cruz) was used to detect His/GST-tagged proteins.

\section{Results}

Direct delivery of heterologous genes from E. coli to insect cells and their expression

To investigate whether foreign genes can be transferred into insect cells by nonpathogenic E. coli strains, the Sf9 cells and BmN-SWU1 cells were infected with recombinant E. coli BL21/egfp. Since the pET30a/egfp contains the egfp gene controlled by the $\mathrm{P}_{\mathrm{T} 7}$ promoter, the EGFP in these two bacterial strains can be induced by IPTG prior to infection. As shown in Fig. 1(a) A and B, and in Fig. 1(b) E and F, the infected insect cells became bright green and the outline of fluorescent cells was apparent at $24 \mathrm{hr}$ p.i.. To further investigate whether $E$. coli-mediated gene delivery is effective in BES, the E. coli strains DH10Bac/egfp and BmDH10Bac/egfp were constructed, in which the recombinant bacmids carry the egfp gene under the control of the baculovirus-insect specific promoter $\mathrm{P}_{\text {Basic }}$. At $72 \mathrm{hr}$ p.i., strong green fluorescence was observed in both Sf9 and BmN-SWU1 cells. Obvious cytopathic effect was also observed at $96 \mathrm{hr}$ p.i. (Fig. 1(a) $\mathrm{C}$ and D, Fig. 1(b) G and H). The titers of the P1 generation baculoviral stocks were determined and with EGFP used as marker. The titration results demonstrated that high-titer BmNPV was obtained by the E. coli-mediated gene delivery. The mean titer was $10^{7.5} \mathrm{PFU} / \mathrm{ml}$ and the highest value reached $10^{8.5} \mathrm{PFU} / \mathrm{ml}$ at $2 \mathrm{hr}$ after the infection at MOI 100 (Fig. 2a and Fig. 2b). Additionally, the entry number of the host cell lines was determined by counting the live internalized bacteria. The entry number in the BmN-SWU1 cell line is approximately 0.6 bacteria per cell (Fig. 3b) and about 0.15 bacteria per cell in Sf9 cell line (Fig. 3a). This result confirmed that $E$. coli strains entered into both insect cell lines.

To test whether the E. coli-mediated gene delivery to insect cells is feasible for the production of baculovirus and heterologous protein, several His/GST-tagged proteins were expressed in BmN-SWU1 cells by E. coli-mediated gene delivery. After collecting the proteins from the infected cell culture, we used western blot to analyze the recombinant protein. The results indicated that proteins of the correct size were successfully expressed in BmN-SWU1 cells (Fig. 4).

Susceptibility of BmN-SWU1 and Sf9 cells to the E. colimediated gene delivery

Both Sf9 and BmN-SWU1 cell lines were successfully infected with the E. coli BL21/egfp (Fig. 1a and Fig. 1b). However, the number of fluorescent cells and the fluorescence intensity were different between the two cell lines. The fluorescence intensity of the BmN-SWU1 cells was much stronger than that of the Sf9 cells, and high-titer baculoviral stocks were always harvested from the BmN-SWU1 cells (Fig. 1b). It was difficult to determine the optimal conditions, such as MOI and time p.i., for virus production in Sf9 cells. The titer of the Sf9-generated P1 baculoviral stocks was much lower than that of the BmN-SWU1 cell (data not shown).

To investigate the difference in the P1 generation baculoviral stocks fluorescence intensity and virus titers between Sf9 and BmN-SWU1 cell lines, the number of live internalized bacteria was quantified. After the infection for $2 \mathrm{hr}$, the number of bacteria released by lysis of the insect cells was determined on appropriate antibiotics containing LB agar plates. The results showed that the amount of live bacteria 
(a)

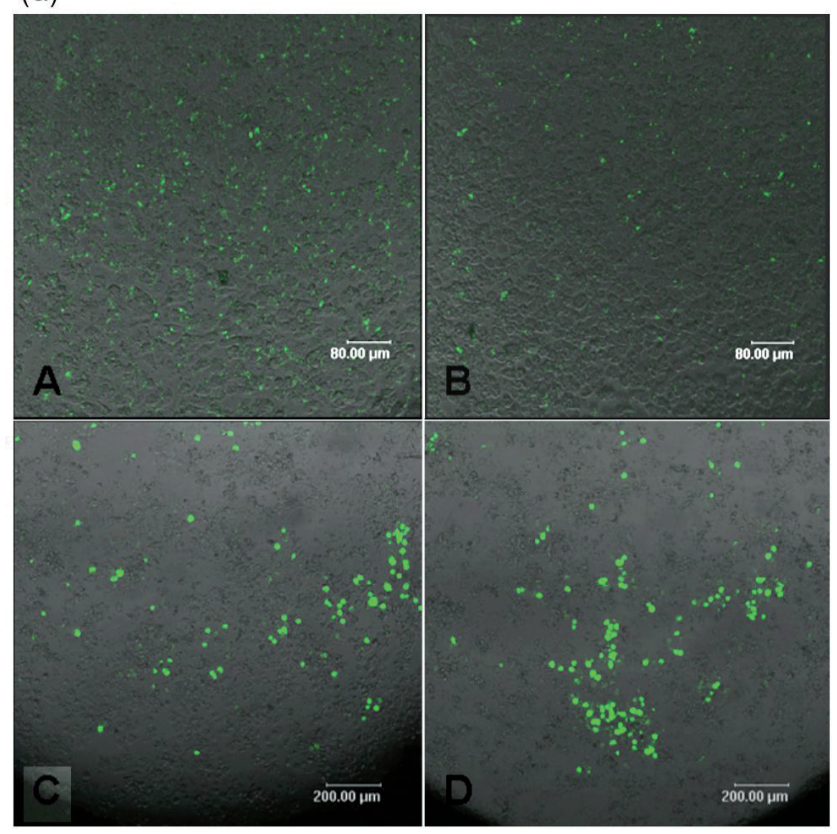

(b)

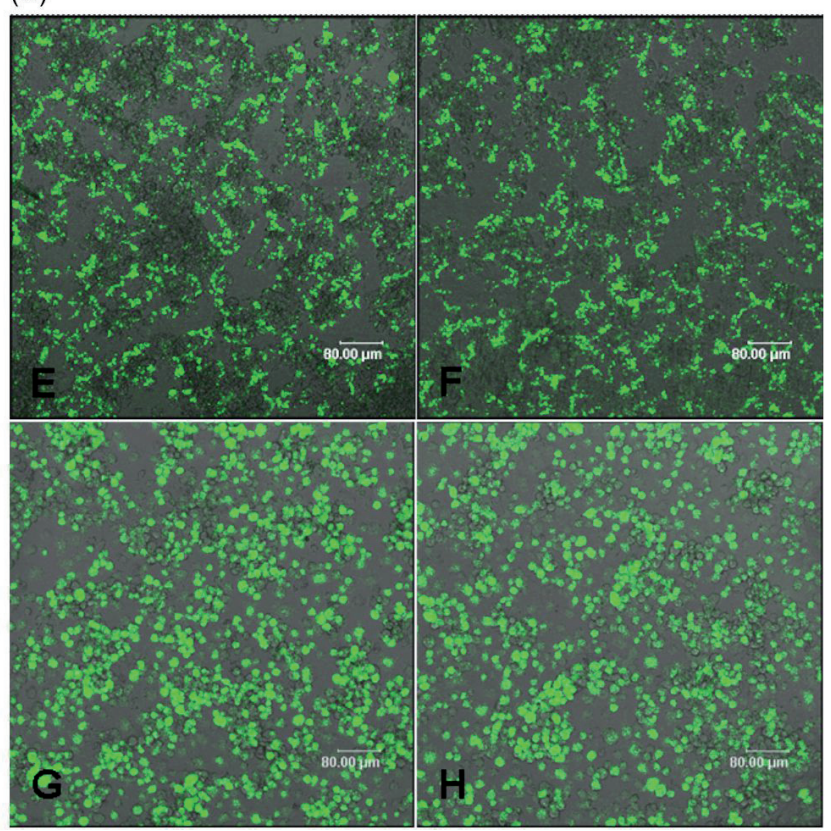

Fig. 1

EGFP expression in insect cells through $E$. coli-mediated gene delivery

Fluorescent microscopy at $24 \mathrm{hr}$ p.i. (A, B, E, F) and $96 \mathrm{hr}$ p.i. (C, D, G, H). (a) Sf9 cells infected with E.coli BL21/egfp strain (A), E. coli BL21/egfp/ $\Omega$ strain (B), E. coli DH10Bac/egfp strain (C) and E.coli DH10Bac/egfp/ $\Omega$ strain (D). (b) BmN-SWU1 cells infected with E. coli BL21/egfp strain (E), E. coli BL21/egfp/ $\Omega$ strain (F), E. coli BmDH10Bac/egfp strain (G), and E. coli BmDH10Bac/egfp/ $\Omega$ strain (H).

internalized by BmN-SWU1 cells was higher than that internalized by Sf9 cells (Fig. 3 a,b). The number of internalized bacteria per cell reached 0.61 at MOI 150 when BmN-SWU1 cells were infected with E. coli BmDH10Bac/egfp. This entry number slowly decreased with the MOI increasing (Fig. 3b). The number of internalized bacteria per cell in Sf9 cells reached its maximum of 0.13 at MOI 500 when the cells were infected with E. coli DH10Bac/egfp. These results are consistent with the titers obtained from both the Sf9 and BmN-SWU1 cell lines.

Co-expression of invasin and listeriolysin-O is dispensable for the E. coli-mediated gene delivery

pGB2Sinv-hly was reported to improve the level of bacteria-mediated gene delivery to mammalian cells (Grillot-Courvalin et al., 1998). In this study, we tested whether the pGB2Sinv-hly enhances the efficiency of the E. coli-mediated gene delivery to insect cells. Sf9 and BmN-SWU1 cell lines were infected by the $E$. coli host strains BL21/egfp and BL21/egfp/ $\Omega$, respectively, as shown in Fig. 1(a) A, B and Fig. 1(b) E, F. The fluorescence results in infected insect cells showed little difference in the presence or absence of pGB2 $2 i n v$-hly. To further confirm the role of pGB2 2 inv-hly in the E. coli-mediated gene delivery for insect cells, E. coli DH10Bac/egfp $/ \Omega$ and $E$. coli $\mathrm{BmDH} 10 \mathrm{Bac} / \mathrm{egfp} / \Omega$ strains containing both recombinant baculovirus bacmids and pGB2Sinv-hly were constructed, and the Sf9 and BmN-SWU1 cells were infected with these recombinant host strains. As shown in Fig. 1(a) C, D and Fig. 1(b) G, H, the fluorescence in insect cells was virtually identical in the presence and absence of pGB2Sinv-hly. Meanwhile, the titers of P1 generation baculoviral stocks displayed no significant difference in the presence or absence of the pGB2Sinv-hly in the host strain. However, the titers in BmN-SWU1 cells infected with E.coli $\mathrm{BmDH} 10 \mathrm{Bac} / \mathrm{egfp} / \Omega$ were higher than those in Sf9 cells infected with E. coli DH10Bac/egfp at MOI $<100$ (Fig. 2a,b). These results demonstrated that the pGB2Sinv-hly is dispensable for E. coli-mediated gene delivery into insect cells, which is different from the bacterial gene delivery into mammalian cells (Grillot-Courvalin et al., 1998). Under the same conditions, the amount of live internalized bacteria with the pGB2 $\Omega i n v$ - $h l y$ was generally lower than that without pGB2Sinv-hly in both the Sf9 and the BmN-SWU1 cell lines (Fig. 3a,b). 
(a)

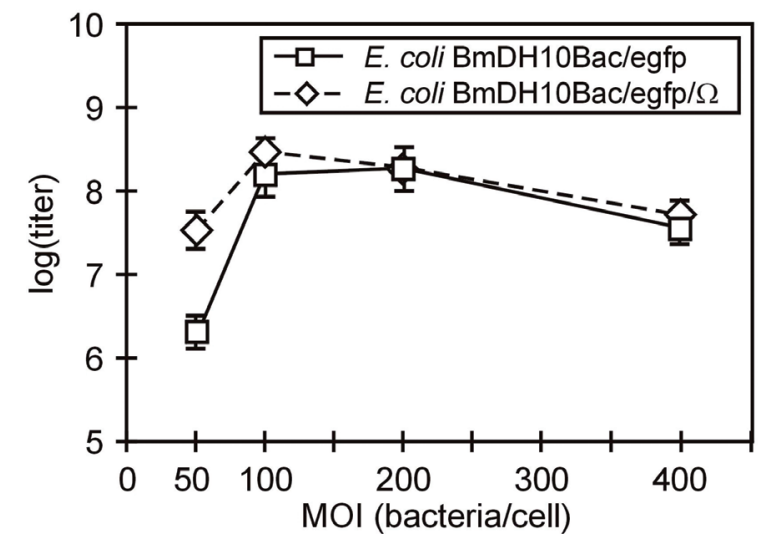

(b)

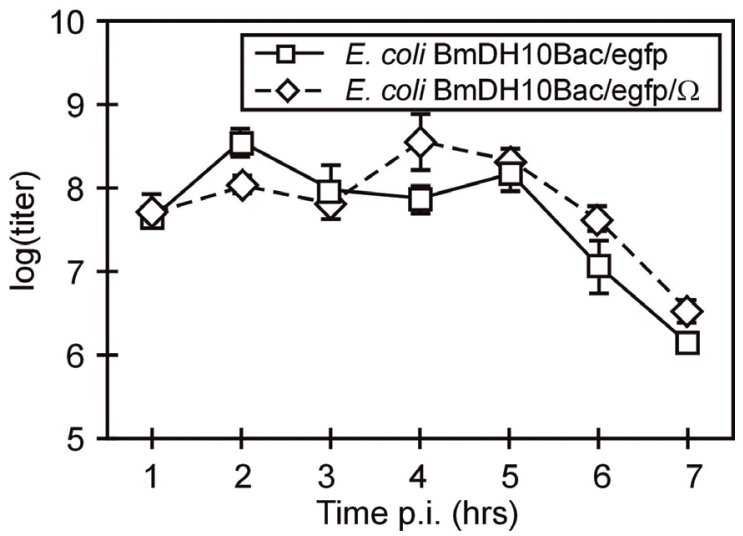

Fig. 2

Production of recombinant baculovirus by BmN-SWU1 cells following the E. coli-mediated gene delivery under various experimental conditions (a) The cells were infected with different $E$. coli strains at different MOI and the virus was harvested at t.o.i. of $2 \mathrm{hr}$ (b) The cells were infected with different $E$. coli strains at MOI of 100 and the virus was harvested after different times of infection.

Effect of various experimental conditions on the E.colimediated gene delivery and expression

To reach maximum efficiency of the E. coli-mediated gene delivery to insect cells, a series of bacterial infection experiments with MOI ranging from MOI 0 to MOI 500 were tested. High-titer baculoviral stocks $\left(\geq 10^{8.0} \mathrm{pfu} / \mathrm{ml}\right)$ were obtained in BmN-SWU1 cell culture infected with E. coli $\mathrm{BmDH} 10 \mathrm{Bac} / \mathrm{egfp} / \Omega$ at the MOI 100 to 300 at time p.i. of 2 hr (Fig. 2b). There was a peak in the curve near the MOI 100, then the titers of baculoviral stocks gradually decreased with the increasing MOI. However, the titers remained at a higher level when BmN-SWU1 cells were infected with E. coli $\mathrm{BmDH} 10 \mathrm{Bac} / \mathrm{egfp}$ or $E$. coli BmDH10Bac/egfp/ $\Omega$ at MOI varying from 100 to 400 . The infected cells detached from the plate with cytopathic effect when the MOI reached 500 .

At the same time, we tried to determine the time of infection (t.o.i.) that would be optimal for harvesting a hightiter baculoviral stock. These experiments were performed following an infection at MOI 200. The results showed that the titers varied with time of infection, at which the virus was harvested (Fig. 2b). Denary logarithms of the titers were maintained at 8.0 at t.o.i. from $2 \mathrm{hr}$ to $5 \mathrm{hr}$ and the maximum value reached 8.5. The highest titer of baculoviral stocks was (a)

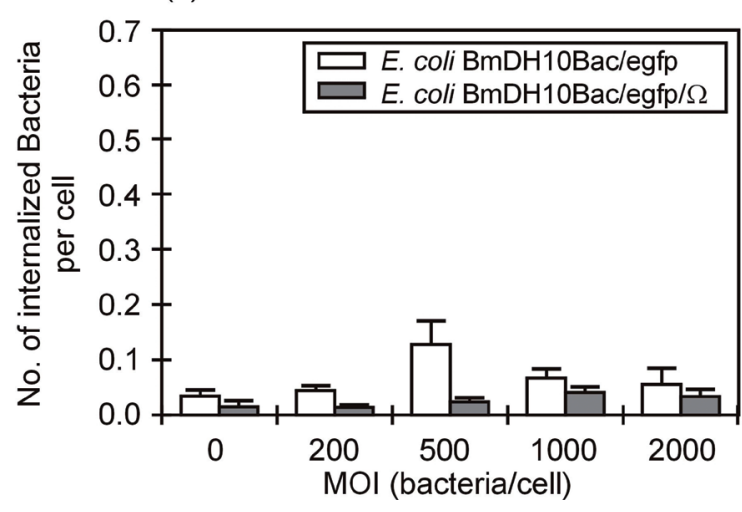

(b)

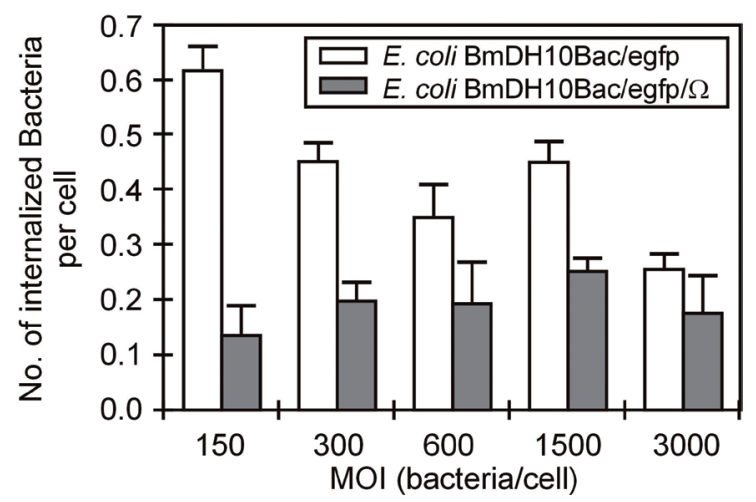

Fig. 3

Internalization of different bacterial strains by insect cells (a) Sf9 cells were infected with $E$. coli DH10Bac/egfp and E. coli DH10Bac/egfp/ $\Omega$ strains at various MOI. (b) BmN-SWU1 cells were infected with E. coli $\mathrm{BmDH} 10 \mathrm{Bac} / \mathrm{egfp}$ and E. coli $\mathrm{BmDH} 10 \mathrm{Bac} / \mathrm{egfp} / \Omega$ strains at various MOI. 


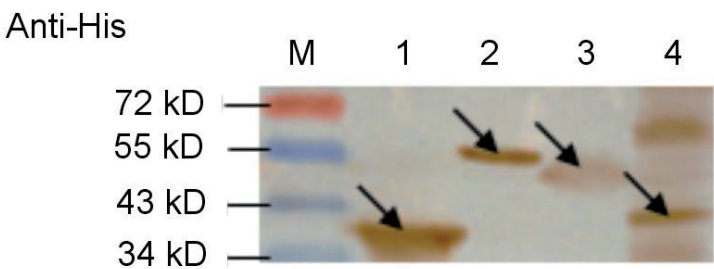

Anti-GST

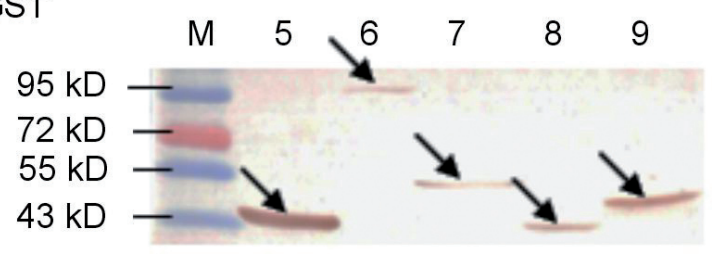

Fig. 4

Expression of various eukaryotic proteins in BmN-SWU1 cells by the E. coli-mediated gene delivery

His-tagged proteins detected with the anti-his monoclonal antibody (lanes 1-4), GST-tagged proteins detected with the anti-GST monoclonal antibody (lanes 5-9), protein size marker (lanes M).

obtained after 2 hrs of infection when BmN-SWU1 cells were infected with E. coli BmDH10Bac/egfp and the viral stock with the highest titer was harvested at t.o.i. $4 \mathrm{hr}$ when BmN-SWU1 cells were infected with E. coli BmDH10Bac/ $\operatorname{egfp} / \Omega$. To our surprise, the titers of the baculoviral stocks were near their maximal levels $\left(>10^{7.0} \mathrm{PFU} / \mathrm{ml}\right)$ at $0.5 \mathrm{hr}$ of infection. The titers increased only slightly with the increasing time of infection. However, the titer decreased sharply at the t.o.i. of 6 hrs and the tendency of the titer curves in $\mathrm{BmN}$ SWU1 cells were very similar in the presence or absence of pGB2 2 inv-hly. We performed similar experiment with Sf9 cells, but the results were irreproducible, maybe due to the differences in the cell lines (data not shown).

\section{Discussion}

The baculovirus-insect cell expression system is one of the most useful eukaryotic expression systems. However, it would be more extensive if there was an efficient gene delivery method for transferring large-size bacmid DNA into the insect cells. It is difficult to prepare and transfect the baculovirus bacmid DNA because of its large size (about $130 \mathrm{~kb}$ ). Such as, keeping large bacmid DNA intact is nearly impossible during the processes of extraction and purification. In addition, the transfection of bacmid DNA into the insect cells is time-consuming and laborious.

Recently, the use of pathogenic and nonpathogenic bacteria to transfer exogenous genetic materials into many kinds of mammalian cells and animal tissues to express antigens, enzymes and pharmaceutical agents became popular (Laner et al., 2005; Vassaux et al., 2006). Here, we developed a method of bacteria-mediated gene delivery to insect cells, which is more simple and effective than traditional BAC-to-BAC system. Simply, the egfp marker gene was transferred into insect cell lines Sf9 or BmN-SWU1 only by the "infection" with the recombinant E. coli strain. EGFP was under the control of the prokaryotic promoter $\mathrm{P}_{\mathrm{T} 7}$ and induced prior to bacterial infection. This result showed that the nonpathogenic $E$. coli strain may be used as a vehicle for transferring foreign genes into insect cells. Based on these results, we constructed recombinant E. coli DH10B strain containing recombinant baculovirus bacmid for transferring egfp gene, which is under the control of late basic promoter $\mathrm{P}_{\text {Basic }}$, into insect cells. The results showed that the infected cells were produced green fluorescence at $72 \mathrm{hr}$ p.i., and the virus titer of P1generation baculoviral stock was equal to that obtained from CellFECTIN-transfected BmN-SWU1 cells, which reached $10^{7}-10^{8} \mathrm{PFU} / \mathrm{ml}$. The above results indicated that the bacmid DNA had been delived into insect cells and baculoviruses had proliferated successfully. Therefore, the $E$. coli-mediated gene delivery provided an alternative for direct transfer of baculovirus bacmid DNA into insect cells.

However, we found that there were fewer cells with green fluorescence in Sf9 cells than in BmN-SWU1 cells when the cells were infected with the internalized baculoviral stocks. Experiment studying internalization of bacteria further confirmed that nonpathogenic recombinant E. coli strains were more efficient at entering the BmN-SWU1 cell line than the Sf9 cell line. It suggested that the efficiency of the E. coli-mediated gene delivery to insect cells varied widely in different cell types, which corresponded with results from bacterial infection of mammalian cell lines (GrillotCourvalin et al., 2002; Hense et al., 2001).

The pGB2Sinv-hly has been shown to enhance the efficiency of the bacteria-mediated gene delivery to mammalian cells (Grillot-Courvalin et al., 1998). But in our study, when Sf9 and BmN-SWU1 cells were infected with recombinant E. coli BL21 strain containing either pET30a/egfp or pGB2Sinv-hly, the intensity of the fluorescence was not enhanced in either of the two cell lines. Titers of baculoviral stocks harvested from either Sf9 or BmN-SWU1 cells did not increase in the presence of pGB2Sinv-hly. These results suggested that the pGB2 $\Omega i n v$-hly does not enhance the efficiency of the E. coli-mediated gene delivery to insect cells.

The efficiency of $E$. coli-mediated gene delivery to insect cells was affected by MOI and time post infection. The results of the MOIs experiment with varying time of infection showed that the high-titer P1 generation baculoviral stocks could be obtained from the infected BmN-SWU1 cells under optimized conditions. Titers of baculoviral stocks maintained a high level when the MOIs ranged from 100 to 300 and the highest level was reached at the point of MOI $100\left(1.0 \times 10^{8.5} \mathrm{PFU} / \mathrm{ml}\right)$. The internalized bacteria 
quantitation test indicated that the highest infection rate of the BmN-SWU1 cells was at MOI 150. However, the cell death was observed with the MOI increasing (up to 500), which could be the result of the bacterial toxicity. Time of infection was another important factor that influenced the production of baculoviruses. In this research, we found that the titers remained at high level when time of infection varied from $1 \mathrm{hr}$ to $5 \mathrm{hr}$ at the MOI of 200, which demonstrated that periods of $1 \mathrm{hrs}$ to $5 \mathrm{hrs}$ would be suitable to produce high-titer baculoviral stocks. When the t.o.i. increased ( $>5$ $\mathrm{hr}$ ), the infected cells began to detach, resulting in decrease in production of baculoviruses. Therefore, it is recommended using MOI of 200 and t.o.i. of $2 \mathrm{hr}$ when BmN-SWU1 cells are infected by recombinant host strains. The method of $E$. coli-mediated baculovirus bacmid delivery to insect cells is feasible and efficient for BES. It eliminated the need for extraction and purification of the baculovirus bacmids and enables a direct transfer of foreign genes into insect cells by means of recombinant $E$. coli strains.

The traditional Bac-to-Bac recombinant baculovirus system has been used to efficiently deliver genes into mammalian cells and has been applied for the gene therapy and vaccination ( $\mathrm{Hu}, 2005)$, but it is expensive and timeconsuming. Now we have established a simple process for harvesting a large quantity of P1 generation baculoviral stocks just by an E. coli-mediated gene delivery to insect cells instead of the traditional transfection. Sufficient amounts of P1 generation baculoviruses avoided the damaging effects caused by repeated passaging, which always lead to a reduced expression of proteins of interest (Pijlman et al., 2001). Cell lines derived from Bombyx mori and silkworm larvae have always been used extensively as bioreactors for protein production (Mathavan et al., 1995), the superiority of E. coli-mediated gene delivery to BmN-SWU1 cells may accelerate its development. It could also promote the popularization for BES if the $E$. coli-mediated gene delivery can introduce the nuclear polyhedrosis virus into the insect cells (Kondo and Maeda, 1991). Therefore, it is possible that applications of baculovirus can be improved remarkably if a large number of baculoviruses were obtained easily by the E. coli-mediated gene delivery. Additionally, mechanisms of gene transfer from bacteria to mammalian cells have already been intensively studied. Putative specific surface proteins mediated recognition and attachment between bacteria and host cells, which was followed by entry, maturation, nuclear import and integration of functional genetic molecules into the host cells (Citovsky et al., 2007).

Our results showed that it was possible to express several eukaryotic proteins successfully in BmN-SWU1 cells, using the $E$. coli-mediated gene delivery to infect insect cells. It predicts a prosperous future for high-throughput protein expression aiding the investigation of the structural and functional analysis of proteins and protein-protein interactions.
Acknowledgement. This work was supported by the grants No. 31340036 and 31172320 from the National Natural Sciences Foundation of China, No. D20111004 from the Science Project of Hubei Provincial Department of Education and No. 201050231086 from the Youth Scientist Project of Wuhan City. The authors thank Dr. Grillot-Courvalin C, Dr. Felix Freuler and Dr. Enoch Y. Park for donating plasmids and bacterial strains.

\section{References}

Ashour M, Ragheb, D, El-Sheikh el-S, Gomaa el-A, Kamita S, Hammock B (2007): Biosafety of recombinant and wild type nucleopolyhedroviruses as bioinsecticides. Int. J. Environ. Res. Public Health 4, 111-125. http://dx.doi.org/10.3390/ ijerph2007040005

Bangham A (1992): Liposomes: realizing their promise. Hosp. Pract. 27, 51-62.

Belzhelarskaia S (2002): A baculovirus expression system for insect cells. Mol. Biol. 36, 371-385.

Cha H, Gotoh T, Bentley W (1997): Simplification of titer determination for recombinant baculovirus by green fluorescent protein marker. Biotechniques 23, 782-786.

Citovsky V, Kozlovsky S, Lacroix B, Zaltsman A, Dafny-Yelin M, Vyas S, Tovkach A, Tzfira T (2007): Biological systems of the host cell involved in Agrobacterium infection. Cell. Microbiol. 9, 9-20. http://dx.doi.org/10.1111/j.1462-5822 $.2006 .00830 . x$

Courvalin P, Goussard S, Grillot-Courvalin C (1995): Gene transfer from bacteria to mammalian cells. C R Acad Sci III. 318, 1207-1212.

Darji A, Guzmán C, Gerstel B, Wachholz P, Timmis K, Wehland J, Chakraborty T, Weiss S (1997): Oral somatic transgene vaccination using attenuated $\mathrm{S}$. typhimurium. Cell 91, 765-775. http://dx.doi.org/10.1016/S0092-8674(00)80465-1

Dietrich G, Bubert A, Gentschev I, Sokolovic Z, Simm A, Catic A, Kaufmann S, Hess J, Szalay A, Goebel W (1998): Delivery of antigen-encoding plasmid DNA into the cytosol of macrophages by attenuated suicide Listeria monocytogenes. Nat. Biotechnol. 16, 181-185. http:// dx.doi.org/10.1038/nbt0298-181

Ernst W, Grabherr R, Katinger H (1994): Direct cloning into the Autographa californica nuclear polyhedrosis virus for generation of recombinant baculoviruses. Nucl. Acids Res. 22, 2855-2856. http://dx.doi.org/10.1093/ nar/22.14.2855

Grillot-Courvalin C, Goussard S, Courvalin P (2002): Wild-type intracellular bacteria deliver DNA into mammalian cells. Cell. Microbiol. 4, 177-186. http://dx.doi.org/10.1046/ j.1462-5822.2002.00184.x

Grillot-Courvalin C, Goussard S, Huetz F, Ojcius D, Courvalin P (1998): Functional gene transfer from intracellular bacteria to mammalian cells. Nat. Biotechnol. 16, 862-866. http://dx.doi.org/10.1038/nbt0998-862

Hense M, Domann E, Krusch S, Wachholz P, Dittmar K, Rohde M, Wehland J, Chakraborty T, Weiss S (2001): Eukaryo- 
tic expression plasmid transfer from the intracellular bacterium Listeria monocytogenes to host cells. Cell. Microbiol. 3, 599-609. http://dx.doi.org/10.1046/j.14625822.2001.00138.x

Hitchman R, Murguía-Meca F, Locanto E, Danquah J, King L (2011): Baculovirus as vectors for human cells and applications in organ transplantation. J. Invertebr. Pathol. 107, S49-58. http://dx.doi.org/10.1016/j.jip.2011.05.005

$\mathrm{Hu}, \mathrm{Y}$ (2005): Baculovirus as a highly efficient expression vector in insect and mammalian cells. Acta Pharmacol. Sin. 26, 405-416. http://dx.doi.org/10.1111/j.1745-7254 $.2005 .00078 . \mathrm{x}$

Hu Y, Yao K, Wu T (2008): Baculovirus as an expression and/or delivery vehicle for vaccineantigens. Expert Rev. Vaccines 7, 363-371. http://dx.doi.org/10.1586/14760584.7.3.363

Kitts P, Ayres M, Possee R (1990): Linearization of baculovirus DNA enhances the recovery of recombinant virus expression vectors. Nucl. Acids Res. 18, 5667-5672. http://dx.doi. org/10.1093/nar/18.19.5667

Kondo A, Maeda S (1991): Host range expansion by recombination of the baculoviruses Bombyx mori nuclear polyhedrosis virus and Autographa californica nuclear polyhedrosis virus. J. Virol. 65, 3625-3632.

Kost T, Condreay J, Jarvis D (2005): Baculovirus as versatile vectors for protein expression in insect and mammalian cells. Nat. Biotechnol. 23, 567-575. http://dx.doi.org/10.1038/ nbt1095

Laner A, Goussard S, Ramalho A, Schwarz T, Amaral M, Courvalin P, Schindelhauer D, Grillot-Courvalin C (2005): Bacterial transfer of large functional genomic DNA into human cells. Gene Ther. 12, 1559-1572. http://dx.doi. org/10.1038/sj.gt.3302576

Lee H, Krell P (1992): Generation and analysis of defective genomes of Autographa californica nuclear polyhedrosis virus. J. Virol. 66, 4339-4347.

Lin C, Lu C, Luo W, Chang Y, Sung L, Chiu H, Hu Y (2010): Baculovirus as a gene delivery vector for cartilage and bone tissue engineering. Curr. Gene Ther. 10, 242-254. http:// dx.doi.org/10.2174/156652310791321242

Madhan S, Prabakaran M, Kwang J (2010): Baculovirus as vaccine vectors. Curr. Gene Ther. 10, 201-213. http://dx.doi. org/10.2174/156652310791321233

Maeda S, Kawai T, Obinata M, Fujiwara H, Horiuchi T, Saeki Y, Sato Y, Furusawa W (1985): Production of human alphainterferon in silkworm using a baculovirus vector. Nature 315, 592-594. http://dx.doi.org/10.1038/315592a0

Magin-Lachmann C, Kotzamanis G, D'Aiuto L, Cooke H, Huxley C, Wagner E (2004): In vitro and in vivo delivery of intact BAC DNA - comparison of different methods. J. Gene Med. 6, 195-209. http://dx.doi.org/10.1002/jgm.481

Mathavan S, Gautvik V, Rokkones E, Olstad O, Kareem B, Maeda S, Gautvik K (1995): High-level production of human parathyroid hormone in Bombyx mori larvae and $\mathrm{BmN}$ cells using recombinant baculovirus. Gene 167, 33-39. http://dx.doi.org/10.1016/0378-1119(95)00599-4

Motohashi T, Shimojima T, Fukagawa T, Maenaka K, Park E (2005): Efficient large-scale protein production of larvae and pupae of silkworm by Bombyx mori nuclear poly- hedrosis virus bacmid system. Biochem. Biophys. Res. Commun. 326, 564-569. http://dx.doi.org/10.1016/j. bbrc.2004.11.060

Pálffy R, Gardlík R, Hodosy J, Behuliak M, Resko P, Radvánský J, Celec P (2006): Bacteria in gene therapy: bactofection versus alternative gene therapy. Gene Ther. 13, 101-105. http://dx.doi.org/10.1038/sj.gt.3302635

Philipps B, Rotmann D, Wicki M, Mayr L, Forstner M (2005): Time reduction and process optimization of the baculovirus expression system for more efficient recombinant protein production in insect cells. Protein Expression Purif. 42, 211-218. http://dx.doi.org/10.1016/j.pep.2005.03.020

Pijlman G, van den Born E, Martens D, Vlak J (2001): Autographa californica baculoviruses with large genomic deletions are rapidly generated in infected insect cells. Virology 283, 132-138. http://dx.doi.org/10.1006/viro.2001.0854

Pijlman G, van Schijndel J, Vlak J (2003): Spontaneous excision of BAC vector sequences from bacmid-derived baculovirus expression vectors upon passage in insect cells. J. Gen. Virol. 84, 2669-2678. http://dx.doi.org/10.1099/ vir.0.19438-0

Potter H (2001): Transfection by electroporation. Curr. Protoc. Mol. Biol. Chapter: Unit-9.3.

Radford K, Higgins D, Pasquini S, Cheadle E, Carta L, Jackson A, Lemoine N, Vassaux G (2002): A recombinant E. coli vaccine to promote MHC class I-dependent antigen presentation: application to cancer immunotherapy. Gene Ther. 9, 1455-1463. http://dx.doi.org/10.1038/sj.gt.3301812

Sizemore D, Branstrom A, Sadoff J (1995): Attenuated Shigella as a DNA delivery vehicle for DNA-mediated immunization. Science 270, 299-303. http://dx.doi.org/10.1126/ $\underline{\text { science.270.5234.299 }}$

Smith G, Summers M, Fraser M (1983): Production of human beta interferon in insect cells infected with a baculovirus expression vector. Mol. Cell. Biol. 3, 2156-2165.

Suzuki H, Saitoh H, Suzuki T, Takaku H (2009): Baculovirusmediated bispecific short-hairpin small-interfering RNAs have remarkable ability to cope with both influenza viruses A andB. Oligonucleotides 19, 307-316. http:// dx.doi.org/10.1089/oli.2009.0189

Tani H, Abe T, Matsunaga T (2008): Baculovirus vector for gene delivery and vaccine development. Future Virol. 3, 35-43. http://dx.doi.org/10.2217/17460794.3.1.35

Vassaux G, Nitcheu J, Jezzard S, Lemoine N (2006): Bacterial gene therapy strategies. J. Pathol. 208, 290-298. http://dx.doi. org/10.1002/path.1865

Wang S, Balasundaram G (2010): Potential cancer gene therapy by baculoviral transduction. Curr. Gene Ther. 10, 214-225. http://dx.doi.org/10.2174/156652310791321251

Xiang S, Fruehauf J, Li C (2006): Short hairpin RNA-expressing bacteria elicit RNA interference in mammals. Nat. Biotechnol. 24, 697-702. http://dx.doi.org/10.1038/nbt1211

Zabner J, Fasbender A, Moninger T, Poellinger K, Welsh M (1995): Cellular and molecular barriers to gene transfer by a cationic lipid. J. Biol. Chem. 270, 18997-19007. http:// dx.doi.org/10.1074/jbc.270.32.18997 